\title{
Evaluation of Variables in Illicit Drug Use: Does a Controlled Substance Abuse SCReening Tool Identify Illicit Drug Use?
}

\author{
Laxmaiah Manchikanti, MD, Vidyasagar Pampati, MSc, Kim S. Damron, RN, and Carla D. McManus, RN, BSN
}

Study Design: A retrospective, casecontrolled study.

Objective: To identify variables in patients with or without illicit drug use.

Background Information: Studies documenting a high incidence of controlled substance abuse in chronic pain continue to increase. Over the years, multiple evaluation tools have been proposed. The need to identify predictors of aberrant drug related behavior and addiction in patients being treated with controlled substances for pain has been emphasized.

Methods: A total of 150 patients were included in the study. One hundred consecutive urine tests without the presence of illicit

Numerous studies have documented the relatively high incidences of opioid abuse in chronic pain (1-16). Fishbain et al (3), studying drug abuse and dependency in chronic pain patients, concluded that between $3.2 \%$ and $18.9 \%$ of patients have been diagnosed with a substance abuse disorder. Manchikanti et al $(4,5)$ showed that the prevalence of controlled substance abuse in interventional pain management practice settings was $18 \%$ to $24 \%$. Manchikanti et al $(1,6)$ also identified illicit drug use in $14 \%$ to $16 \%$ of patients without controlled substance abuse, and $34 \%$ of patients with controlled substance abuse. Polatin et al (7) identified substance abuse in $19 \%$ of patients with chronic low back pain. Chabal et al (8) showed that $28 \%$ of the patients met three or more drug abuse criteria. Other studies have identified similar rates of drug abuse in patients with chronic pain (9-15). Misuse of prescription controlled substances

From Pain Management Center of Paducah, Paducah, KY. Address Correspondence: Laxmaiah Manchikanti, MD, 2831 Lone Oak Road, Paducah, KY-42003.

E-mail: drm@apex.net

Funding: There was no funding in preparation of this manuscript.

Conflict of Interest: None drugs and 50 consecutive urine tests with the presence of illicit drugs of patients receiving controlled substances, were selected for evaluation of multiple variables of illicit drug use. They were divided into four groups with Group I with no controlled substance abuse and no illicit drug abuse with 70 patients; Group II with no controlled substance abuse, however, with positive illicit drug use with 33 patients; Group III with positive controlled abuse, however, with no illicit drug use with 30 patients; and Group IV with controlled substance abuse and illicit drug use with 17 patients.

Results: Results of this study showed that of the eight variables described in a previous study in identifying controlled substance

may lead to serious health consequences, including increased healthcare costs, drug dependence, overdose, and death $(16,17)$.

Over the years, multiple evaluation tools have been proposed. Several authors have emphasized the need to identify predictors of aberrant drug-related behavior and addiction in patients being treated with controlled substances for pain (1012, 18-23). Thus, compliance with treatment guidelines and development of addiction have been identified as critical areas for patient monitoring. In a recent study, Katz et al (23) reported results of behavioral monitoring and urine toxicology testing in patients receiving long-term opioid therapy in a retrospective evaluation. The results of this retrospective evaluation were disturbing. In this study, for 122 patients maintained on chronic opioid therapy, $43 \%$ "had a problem" (either positive urine toxicology or one or more aberrant drug-taking behaviors). In addition, of patients with no behavioral issues, $21 \%$ had a positive urine screen for either an illicit drug or a non-prescribed controlled medication. Further, of patients with a negative urine screen, $14 \%$ had one or more behavioral issues. The proportion of patients without behavioral issues abuse, four variables were crucial. The four significant items identified in this evaluation were excessive opiate needs, deception or lying to obtain controlled substances, current or prior intentional doctor shopping, and current or prior use of illicit drugs and denial. These four variables were accurate in identifying controlled substance abuse. However, they failed to identify illicit drug use.

Conclusion: The presently available and validated screening tool for controlled substance abuse failed to identify illicit drug use in patients receiving controlled substances.

Keywords: Controlled substance abuse, illicit drug use, drug dependence, substance abuse assessment.

with abnormal urine screens, was similar to overall abnormal urine screens in this study ( $21 \%$ vs $29 \%)$. In this study, $72 \%$ (26 of 36) of patients with positive urine toxicology screens did not evidence any of the behaviors thought to be useful screening tests for these disorders.

Atluri and Sudarshan (13) reported results of failed urine drug screens of 89 patients in an interventional pain management practice. The results showed that $55 \%$ were not taking the prescribed opioid, whereas $39 \%$ were taking opioids that were not prescribed. In addition, $46 \%$ of the patients were using illicit drugs. Multiple characteristics were identified as central to diagnosing addiction in chronic pain population, including the presence of adverse consequences associated with the use of opioids, loss of control over the use of opioids, and pre-occupation with obtaining opioids despite the presence of adequate analgesia.

Traditional indicators of addictive disease in chronic pain patients have typically been those described as drug seeking, such as obtaining medication from multiple providers, repeated episodes of prescription loss, and multiple requests for early refills (23-25). Chabal et al (8) de- 
fined prescription opioid abuse as meeting three or more of the five criteria. They included an overwhelming focus on opiate issues during pain clinic visits, the pattern of early refills or escalating drug use, multiple telephone calls or visits with requests for more opiates, prescription problems, including lost medications, spilled medications, or stolen medications, and opiates obtained from multiple providers, emergency rooms, or illegal sources.

Compton et al (24) identified 3 key screening indicators as excellent predictors for the presence of addictive disease in a sample of chronic pain patients. The three predictive indicators included the patient's belief that he or she is addicted, increasing analgesic dose or frequency, and route of administration preference.

Atluri and Sudarshan (26) identified 5 criteria which included focus on opioids, opioid overuse, other substance use, non-functional status, exaggeration of pain, and unclear etiology for pain. Manchikanti et al (18) in an extensive and prospective evaluation identified 8 important items with positive correlation and high odds ratios (Table 1). On further simplification, they identified 3 criteria, which included excessive opiate needs, deception or lying to obtain controlled substance, and current or prior intentional doctor shopping. Katz et al (23) utilized 5 selected behaviors to identify inappropriate drug-taking behaviors which included the reports of lost or stolen prescriptions, consumption in excess of prescribed dosage, visits without appointments, multiple drug intolerances and allergies, and frequent telephone calls. Friedman et al (26) evaluating a screening questionnaire showed that questions relating to tobacco abuse, prior treatment in a drug or alcohol rehabilitation facility, or treatment in another pain clinic were significantly more common in respondents who had used or were currently using heroin or cocaine.

Interventional pain physicians continue to struggle in striking a balance between managing medically necessary controlled substance usage versus identifying patients with illicit drug use or controlled substance abuse. Thus, this retrospective evaluation was undertaken to identify variables in illicit drug use.

\section{Methods}

In an interventional pain management practice, a total of 150 consecutive patients who underwent random urine

Table 1. Items utilized in this study
\begin{tabular}{|l|}
\hline 1. Past Substance abuse \\
\hline i. Alcohol abuse \\
\hline ii. Benzodiazepine/soma/barbiturate/stimulant use \\
\hline iii. Prior or current illicit drug use, but admits to it \\
\hline 2. Nonfunctional \\
\hline i. On Medicaid \\
\hline ii. On disability (but not retired) \\
\hline iii. On compensation but not working \\
\hline 3. Excessive opiate needs \\
\hline i. Multiple dose escalations \\
\hline ii. Multiple emergency room visits \\
\hline iii. Multiple calls to obtain more opiates \\
\hline iv. Repeatedly asking for higher doses \\
\hline v. Taking opiates or other controlled substances from others \\
\hline 4. Deception or lying to obtain controlled substances \\
\hline 5. Current or prior intentional doctor shopping \\
\hline 6. Current investigation or prior conviction for illicit drugs or opiates \\
\hline 7. Current or prior use of illicit drugs and denial \\
\hline 8. Asking for specific controlled substance or soma \\
\hline
\end{tabular}

drug testing (100 consecutive urine tests without the presence of illicit drugs, and 50 consecutive urine tests with the presence of illicit drugs), receiving controlled substances, were selected for evaluation of multiple variables in illicit drug use. These 150 patients were further divided into 4 groups, based on controlled substance use. Group I - no controlled substance abuse and no illicit drug use $=70$; Group II - no controlled substance abuse with positive illicit drug use $=33$ patients; Group III - positive controlled substance abuse with no illicit drug use $=30$; Group IV - controlled substance abuse plus illicit drug use $=17$. Eight significant items providing positive correlation with significant odds ratio and $P$ values from a previous study (18) were utilized for this evaluation. These items are listed in Table 1.

To provide appropriate evidence for the utility of the 8 items identified in a previous study and determine how well these items discriminate between chronic pain patients with controlled substance abuse with or without illicit drug use, all of the 8 items were evaluated in $150 \mathrm{pa}$ tients. All patients were referred for interventional pain management with various types of problems, with the majority having chronic spinal pain. All patients were on controlled substances prior to admission to the interventional pain management practice. The study design met the Institutional Review Board criteria.

Drug abuse was considered to be the misuse of controlled substances in a clinical setting, including obtaining controlled substances from other physicians or other identifiable sources, dose escalations with inappropriate use, and/or violation of controlled substance agreement.

Data were collected in a preprinted format. Statistical assessment used the chi-squared test and $p$ values $<0.001$ were considered significant.

\section{RESULTS}

A total of 150 patients were evaluated. Group I included 70 patients with no controlled substance abuse and no illicit drug use; Group II included 33 patients with no controlled substance abuse with positive illicit drug use; Group III included 30 patients with positive controlled substance abuse with no illicit drug use, and Group IV included 17 patients with controlled substance abuse plus illicit drug use. Eight signif- 
icant items providing positive correlation with significant odds ratio and $P$ values were utilized for this evaluation (Table 1).
Demographics

As shown in Table 2, there were no differences noted with regards to gender, distribution, height, weight, or mode of onset of pain or history of previous laminectomy.
Factor Analysis

Table 3 shows the responses for eight items and the sub items for all four groups. Responses showed a positive correlation with $P$ value $<0.001$ in four of

Table 2. Demographic Characteristics

\begin{tabular}{|c|c|c|c|c|c|c|}
\hline & & $\begin{array}{c}\text { Group I } \\
\text { No controlled } \\
\text { substance } \\
\text { abuse and no } \\
\text { illicit drug use } \\
\text { (70) }\end{array}$ & $\begin{array}{l}\text { Group II } \\
\text { No controlled } \\
\text { substance } \\
\text { abuse with } \\
\text { positive illicit } \\
\text { drug } \\
\text { (33) }\end{array}$ & $\begin{array}{c}\text { Group III } \\
\text { Positive } \\
\text { controlled } \\
\text { substance } \\
\text { abuse with no } \\
\text { illicit drug use } \\
\text { (30) }\end{array}$ & $\begin{array}{c}\text { Group IV } \\
\text { Controlled } \\
\text { substance } \\
\text { abuse plus } \\
\text { illicit drug use } \\
\quad \text { (17) }\end{array}$ & $P$ value \\
\hline \multirow{2}{*}{ Gender } & Male & $36 \%(25)$ & $52 \%(17)$ & $40 \%(12)$ & $53 \%(9)$ & \multirow{2}{*}{0.3550} \\
\hline & Female & $64 \%(45)$ & $48 \%(16)$ & $60 \%(18)$ & $47 \%(8)$ & \\
\hline Age (yrs.) & Mean \pm SD & $47 \pm 12.3$ & $44 \pm 7.3$ & $46 \pm 14.1$ & $42 \pm 7.7$ & 0.3740 \\
\hline Weight (lbs.) & Mean \pm SD & $184 \pm 45.6$ & $172 \pm 39.1$ & $174 \pm 41.4$ & $163 \pm 27.2$ & 0.1820 \\
\hline Height (inches) & Mean \pm SD & $67 \pm 3.9$ & $67 \pm 3.2$ & $66 \pm 3.96$ & $66 \pm 3.7$ & 0.4590 \\
\hline \multirow{2}{*}{ Mode of onset of pain } & Traumatic & $41 \%(29)$ & $55 \%(18)$ & $50 \%(15)$ & $41 \%(7)$ & \multirow{2}{*}{0.5910} \\
\hline & Non-traumatic & $59 \%(41)$ & $45 \%(15)$ & $50 \%(15)$ & $59 \%(10)$ & \\
\hline Duration of Pain (months) & Mean \pm SD & $109 \pm 59.6$ & $102 \pm 61.1$ & $125 \pm 55.3$ & $116 \pm 44.7$ & 0.4420 \\
\hline \multicolumn{2}{|c|}{ History of previous laminectomy } & $41 \%(29)$ & $55 \%(18)$ & $37 \%(11)$ & $35 \%(6)$ & 0.4290 \\
\hline
\end{tabular}

Table 3. Analysis of multiple factors

\begin{tabular}{|c|c|c|c|c|c|}
\hline & $\begin{array}{l}\text { Group I } \\
(70)\end{array}$ & $\begin{array}{c}\text { Group II } \\
\text { (33) }\end{array}$ & $\begin{array}{l}\text { Group III } \\
\text { (30) }\end{array}$ & $\begin{array}{l}\text { Group IV } \\
(17)\end{array}$ & $P$ Value \\
\hline 1. Past Substance abuse & $59 \%(41)$ & $79 \%(26)$ & $83 \%$ a $(25)$ & $77 \%(13)$ & 0.0380 \\
\hline i. Alcohol abuse & $10 \%(7)$ & $12 \%(4)$ & $10 \%(3)$ & $12 \%(2)$ & 0.9860 \\
\hline ii. Benzodiazepine/soma/barbiturate/stimulant use & $51 \%(36)$ & $55 \%(18)$ & $80 \%{ }^{\text {ab }}(24)$ & $65 \%(11)$ & 0.0540 \\
\hline iii. Prior or current illicit drug use, but admits to it & $1 \%(1)$ & $39 \%^{\mathrm{a}}(13)$ & $0 \%{ }^{b}$ & $35 \%$ ac $(6)$ & 0.000 \\
\hline 2. Nonfunctional & $71 \%(50)$ & $91 \%^{\mathrm{a}}(30)$ & $70^{\mathrm{b}}(21)$ & $94 \%(16)$ & 0.0340 \\
\hline i. On Medicaid & $36 \%(25)$ & $45 \%(15)$ & $27 \%(8)$ & $41 \%(7)$ & 0.4640 \\
\hline ii. On disability (but not retired) & $36 \%(25)$ & $45 \%(15)$ & $43 \%(13)$ & $53 \%(9)$ & 0.5450 \\
\hline iii. On compensation but not working & $0 \%$ & $3 \%(1)$ & $0 \%$ & $0 \%$ & 0.3120 \\
\hline 3. Excessive opiate needs & $3 \%(2)$ & $12 \%(4)$ & $93 \%$ ab $(28)$ & $88 \%^{\mathrm{ab}}(15)$ & 0.0000 \\
\hline i. Multiple dose escalations & $0 \%$ & $0 \%$ & $3 \%(1)$ & $0 \%$ & 0.2590 \\
\hline ii. Multiple emergency room visits & $1 \%(1)$ & $6 \%(2)$ & $13 \%^{a}(4)$ & $23 \%^{a}(4)$ & 0.0130 \\
\hline iii. Multiple calls to obtain more opiates & $0 \%$ & $12 \%^{\mathrm{a}}(4)$ & $23 \%^{a}(7)$ & $29 \%^{\mathrm{a}}(5)$ & 0.0070 \\
\hline iv. Repeatedly asking for higher doses & $1 \%(1)$ & $6 \%(2)$ & $30 \%{ }^{\mathrm{ab}}(9)$ & $18 \%^{\mathrm{a}}(3)$ & 0.0000 \\
\hline $\begin{array}{l}\text { v. Taking opiates or other controlled substances from } \\
\text { others }\end{array}$ & $1 \%(1)$ & $3 \%(1)$ & $90 \%$ ab $(27)$ & $82 \%$ ab $(14)$ & 0.0000 \\
\hline $\begin{array}{l}\text { 4. Deception or lying to obtain controlled } \\
\text { substances }\end{array}$ & $1 \%(1)$ & $3 \%(1)$ & $37 \%$ ab (11) & $41 \%$ ab $(7)$ & 0.0000 \\
\hline 5. Current or prior intentional doctor shopping & $1 \%(1)$ & $0 \%$ & $80 \%$ ab $(24)$ & $65^{\text {ab }}(11)$ & 0.0000 \\
\hline $\begin{array}{l}\text { 6. Current investigation or prior conviction for illict } \\
\text { drugs or opiates }\end{array}$ & $7 \%(5)$ & $6 \%(2)$ & $3 \%(1)$ & $6 \%(1)$ & 0.910 \\
\hline 7. Current or prior use of illicit drugs and denial & $0 \%$ & $52 \%^{a}(17)$ & $0 \%^{b}$ & $47^{\mathrm{ac}}(8)$ & 0.0000 \\
\hline 8. Asking for specific controlled substance or soma & $0 \%$ & $9 \%^{a}(3)$ & $7 \%(2)$ & $12 \%^{a}(2)$ & 0.0700 \\
\hline
\end{tabular}

Group I: No controlled substance abuse and no illicit drug use Group II: No controlled substance abuse with positive illicit drug Group III: Positive controlled substance abuse with no illicit drug use Group IV: Controlled substance abuse plus illicit drug use a. indicates significant difference with Group I

b. indicates significant difference with Group II

c. indicates significant difference with Group III 
Table 4. Analysis of values of items 3,4,5, and 7

\begin{tabular}{|c|c|c|c|c|c|}
\hline \multicolumn{2}{|c|}{} & \multicolumn{4}{|c|}{ Original Group } \\
\cline { 3 - 6 } & $\begin{array}{c}\text { Group I } \\
\text { No controlled } \\
\text { substance abuse } \\
\text { and no illicit drug } \\
\text { use } \\
(70)\end{array}$ & $\begin{array}{c}\text { Group II } \\
\text { No controlled } \\
\text { substance abuse } \\
\text { with positive illicit } \\
\text { drug } \\
(33)\end{array}$ & $\begin{array}{c}\text { Group III } \\
\text { Positive controlled } \\
\text { substance abuse } \\
\text { with no illicit drug } \\
\text { use } \\
(30)\end{array}$ & $\begin{array}{c}\text { Group IV } \\
\text { Controlled } \\
\text { substance abuse } \\
\text { plus illicit drug use }\end{array}$ \\
\hline \multirow{3}{*}{ Total Score } & $\begin{array}{c}<2 \\
\text { (Non-abuse) }\end{array}$ & $100 \%(70)$ & $94 \%(31)$ & $20 \%(6)$ & $23 \%(4)$ \\
\cline { 2 - 6 } & $\begin{array}{c}\geq 2 \\
\text { (Abuse) }\end{array}$ & $0 \%$ & $6 \% \%^{\mathrm{a}(2)}$ & $80^{\mathrm{ab}}(24)$ & $77^{\mathrm{ab}}(13)$ \\
\hline
\end{tabular}

a indicates significant difference with Group b indicates significant difference with Group II c indicates significant difference with Group III

the eight items. These included excessive opiate needs, deception or lying to obtain controlled substances, current or prior intentional doctor shopping, and current or prior use of illicit drugs and denial.

We analyzed the value of items 3,4 , 5 and 7 : excessive opiate needs, deception or lying to obtain controlled substances, current or prior intentional doctor shopping, current or prior use of illicit drugs and denial (Table 4). If the total score was 2 or greater, the results showed a positive correlation in Group III and IV with controlled substance abuse, with or without illicit drug usage. However, there was no correlation noted in Group II with patients using illicit drugs but with no evidence of controlled substance abuse. Further, patients with a score of less than 2 had an excellent correlation with Group I and II without controlled substance abuse, with or without illicit drug use.

\section{Discussion}

This retrospective study of illicit drug abuse with or without controlled substance abuse failed to confirm that the previously described criteria for identifying controlled substance abuse $(8,18,19$, 24) were able to identify illicit drug use. This study demonstrated similar results as our previous study (18) in identifying patients with controlled substance abuse. The four significant items identified in this evaluation, excessive opiate needs, deception or lying to obtain controlled substances, current or prior intentional doctor shopping, and current or prior use of illicit drugs and denial failed to identify illicit drug abusers. However, these variables were unable to indetify patients using illict drugs. As Katz et al (23) identi- fied in their evaluation, monitoring of behavioral issues alone or urine drug testing alone will not suffice. Thus, it appears that monitoring both urine toxicology and behavioral issues will identify a greater number of patients with controlled substance abuse and/or illicit drug use.

This study demonstrated that the majority of the patients (70 of 150) did not abuse controlled substances or illicit drugs. However, a significant proportion of patients (33 of 103) without controlled substance abuse, were positive for illicit drug use. The study identified accurately Group III patients with positive controlled substance abuse even though they had no evidence of illicit drug abuse (30 of 47 patients). Finally, the study also identified appropriately Group IV patients with controlled substance abuse and illicit drug use. Thus, the screening evaluation tool appropriately identified all patients with controlled substance abuse, but, failed to selectively identify those using illicit drugs.

The results were also in contradiction to the study by Atluri and Sudarshan (19) in which they studied 107 patients in an abuse group and 103 in a control group. Patients included in the abuse group were consecutive patients with chronic nonmalignant pain who failed a urine drug test. After evaluating multiple variables, they determined that six variables were significant associated with abuse behavior. These included a focus on opioids, opioid overuse, other substance abuse, non-functional behavior, unclear etiology of pain, and exaggeration of pain. On the other hand our evaluation for screening specifically for controlled substance abuse (18) correlated well with most of the criteria as described by Atluri and $\mathrm{Su}$ darshan (19).

This study may be criticized for several reasons including the definition of drug abuse, type of urine drug testing, and the retrospective nature of the study. Investigators preoccupied with "opiophobia" and pseudoaddiction may criticize the definition of drug abuse utilized in this study. However, it does not appear that the terms opiophobia or pseudoaddiction are justified. The definition of pseudoaddiction was based on a single patient with cancer pain, with well-defined pathology, who was under treated with parenteral opioids prescribed on an as needed basis (27). In contrast, all patients involved in the present study differed grossly from the single patient described in the widely quoted article on pseudoaddiction (27). None of our patients were suffering with malignancy, pain of less than six months' duration, or psychogenic pain. All the patients were considered to have a structural basis for pain and were evaluated with available methodology including radiological evidence and precision diagnostic blocks using interventional techniques. They were all determined to be medically stable for at least one year prior to being included in the study.

The mode of identification of illicit drug usage by urine testing also may be criticized. However, this is the most efficient and accurate means of testing in a practice setting.

Finally, we may be criticized for retrospective nature of this evaluation. A prospective or a randomized evaluation would be extremely difficult.

In summary, the assessment criteria developed and validated in a screening 
tool for identification of controlled substance abuse failed to selectively identify illicit drug abuse in patients taking controlled substances.

\section{Conclusion}

This study failed to validate screening criteria previously shown to be useful for identifying controlled substance abuse for the selective detection of illicit drug use. However, these criteria were useful in identifying drug abuse, confirming the previous evaluations. Selective identification of illicit drug use currently requires urine or blood testing.

Author Affiliation:
Laxmaiah Manchikanti, MD
Medical Director
Pain Management Center of Paducah
2831 Lone Oak Road
Paducah, KY-42003
E-mail drm@apex.net
Vidyasagar Pampati, MSc
Statistician
Pain Management Center of Paducah
2831 Lone Oak Road
Paducah, KY-42003
E-mail sagar@thepainmd.com
Kim S. Damron, RN
Clinical Coordinator
Pain Management Center of Paducah
2831 Lone Oak Road
Paducah, KY-42003
E-mail: kim@thepainmd.com
Carla D. McManus, RN, BSN
Clinical Coordinator
Pain Management Center of Paducah
2831 Lone Oak Road
Paducah, KY-42003
E-mail: carla@thepainmd.com

\section{Author Affiliation:}

Medical Director

Pain Management Center of Paducah

2831 Lone Oak Road

Paducah, KY-42003

E-maildrm@apex.net

\section{Vidyasagar Pampati, MSc}

Pain Management Center of Paducah 2831 Lone Oak Road

Paducah, KY-42003

E-mailsagar@thepainmd.com

Pain Management Center of Paducah 2831 Lone Oak Road

Paducah, KY-42003

Carla D. McManus, RN, BSN

Clinical Coordinator

Pain Management Center of Paducah

Paducah, KY-42003

E-mail: carla@thepainmd.com

\section{REFERENCES}

1. Manchikanti L, Pampati V, Damron K et al. Prevalence of illicit drug use in patients without controlled substance abuse in interventional pain management. Pain Physician 2003; 6:173-178.

2. Lewin ICF. Analysis of Prescription Monitoring Programs. Prepared for HoffmanLaRoche by Lewin ICF. Washington DC, April 26, 1991.

3. Fishbain DA, Rosomoff HL, Rosomoff RS. Drug abuse, dependence, and addiction in chronic pain patients. Clin J Pain 1992; 8: 77-85.

4. Manchikanti L, Pampati V, Damron K et al. Prevalence of opioid abuse in interventional pain medicine practice settings: A randomized clinical evaluation. Pain Physician 2001; 4:358-365.

5. Manchikanti L, Pampati V, Damron K. Prevalence of prescription drug abuse and dependency in patients with chronic pain in western Kentucky. J KY Med Assoc 2003; 101:329-335.

6. Manchikanti L, Beyer C, Damron K et al. A comparative evaluation of illicit drug use in patients with or without controlled substance abuse in interventional pain management. Pain Physician 2003; 6:281286.

7. Polatin PB, Kinney RK, Gatchel RJ et al. Psychiatric illness and chronic low back pain: The mind and the spine - which goes first? Spine 1993; 18:66-71.

8. Chabal C, Erjavec MK, Jacobson L et al. Prescription opiate abuse in chronic pain patients: Clinical criteria, incidence, and predictors. Clin J Pain 1997; 13:150-155.

9. Atluri S, Boswell M, Hansen $\mathrm{H}$ et al. Guidelines for the use of controlled substances in the management of chronic pain. Pain Physician 2003; 6:233-257.

10. Fishman SM, Wilsey B, Yang J et al. Adherence monitoring and drug surveillance in chronic opioid therapy. J Pain Symptom Manage 2000; 20:293-307.

11. Sees KL, Clark W. Opioid use in the treatment of chronic pain: Assessment of addiction. J Pain Symptom Manage 1993; 8: 257-264.

12. Pancratz L, Hickman DH, Toth S. The identification and management of drug-seeking behavior in a medical center. Drug Alcohol Depend 1989; 24:115-118.

13. Atluri S, Sudarshan G. Evaluation of abnormal urine drug screens among patients with chronic non-malignant pain treated with opioids. Pain Physician 2003; 6:407409.

14. Fishbain DA. Report on the prevalence of drug/alcohol abuse and dependence in chronic pain patients (CPPs). Subst Use Misuse 1996; 31:945-946.

15. Haller DL, Butler S. Use and abuse of prescription and recreational drugs by chronic pain patients. In Harris LS (ed). Prob- lems of drug dependence, 1990. Washington DC: GPO, 1991: 456-457.

16. Substance Abuse and Mental Health Services Administration, Office of Applied Studies. National Survey of Substance Abuse Treatment Services (N-SSATS): 2002. Data on Substance Abuse Treatment Facilities, DASIS Series: S-19, DHHS Publication No. (SMA) 03-3777, Rockville, MD, 2003.

17. American Medical Association. Curtailing prescription drug abuse while preserving therapeutic use: American Medical Association recommendations for drug control policy. In Wilford BB (ed). Balancing the Response to Prescription Drug Abuse. American Medical Association, Chicago, 1990, pp 273-298.

18. Manchikanti L, Singh V, Damron KS et al. Screening for controlled substance abuse in interventional pain management settings: Evaluation of an assessment tool. Pain Physician 2003; 6:425-434.

19. Atluri S, Sudarshan G. A screening tool to determine the risk of prescription opioid abuse among patients with chronic nonmalignant pain. Pain Physician 2002; 5: 447-448.

20. Dunbar SA, Katz NP. Chronic opioid therapy for nonmalignant pain in patients with a history of substance abuse: Report of 20 cases. J Pain Symptom Manage 1996; 11: 163-171

21. Coambs R, Jarry JL, Santhiapillai AC et al. The SISAP: A new screening instrument for identifying potential opioid abusers in the management of chronic nonmalignant pain within general medical practice. Pain Res Manage 1996; 1:155-162.

22. Passik SD, Whitcomb L, Dodd S et al. Pain outcomes in long-term treatment with opioids: Preliminary results with a newly developed physician checklist. The fourth conference on pain management and chemical dependency. Washington, DC; 2000.

23. Katz NP, Sherburne S, Beach M et al. Behavioral monitoring and urine toxicology testing in patients receiving long-term opioid therapy. Anesth Analg 2003; 97:1097-1102.

24. Compton P, Darakjian J, Miotto K. Screening for addiction in patients with chronic pain and "problematic" substance use: Evaluation of a pilot assessment tool. J Pain Symptom Manage 1998; 16:355-363

25. Portenoy RK. Opioid therapy for chronic non-malignant pain: Current status. In Fields HL, Liebeskind JC (eds). Progress in Pain Research and Management, Vol. 1. IASP Press, Seattle, 1994:247-287.

26. Friedman R, Li V, Mehrotra D. Treating pain patients at risk: Evaluation of a screening tool in opioid-treated pain patients with and without addiction. Pain Med 2003; 4: 182-185.

27. Weissman DE, Haddox JD. Opioid pseudoaddiction: An iatrogenic syndrome. Pain 1989; 36:363-366. 
